\title{
Synthesis and Characterization of a Novel Mid-Chain Macrophotoinitiator of Poly(methyl methacrylate) by $\mathrm{Ce}(\mathrm{IV}) / \mathrm{HNO}_{3}$ Redox System
}

\author{
By Mustafa DegirmenCI, ${ }^{1, *}$ Mehmet Ali AKBULUT, ${ }^{1}$ Sirin HICRI, ${ }^{1}$ and Hasim YILMAZ $^{2}$
}

Dihydroxy functional photoinitiator namely, 2-hydroxy-1-[4-(2-hydroxyethoxy)phenyl]-2-methyl propan-1-one (HE-HMPP), Irgacure 2959, has been used as reducing agent in redox initiated free-radical polymerization of methyl methacrylate (MMA) in conjunction with cerium(IV) ammonium nitrate in aqueous nitric acid at $40^{\circ} \mathrm{C}$ to obtain a novel mid-chain macrophotoinitiator of poly(MMA). The effects of Ce(IV), HE-HMPP, and MMA concentrations on the polymerization rate were investigated. The IR, H NMR, UV, photodegradation, and fluorescence spectroscopic studies revealed that poly(methyl methacrylate) with desired photoinitiator functionality in the polymer chain was obtained. This prepolymer was used in photoinduced free radical polymerization of acrylamide (AAm) and acrylonitrile (AN) to produce block copolymer.

KEY WORDS: Redox Polymerization / Macrophotoinitiator / Functional Polymer / Poly(methyl methacrylate) / Block Copolymer /

Redox reaction systems of Ce(IV) salts with reducing agents like alcohols, aldehydes, ketones, acids, amines, thiols, etc. in aqueous solution are well-known initiators for vinyl polymerization. ${ }^{1,2}$ Compared to the other methods, redox reaction systems have the prime advantage of very short induction time, low activation energy, synthesis of high molecular weight polymers, and easy control of polymerization reactions at moderate temperatures due to minimizing of side reactions, and direct experimental proof of transient radical intermediates. Homopolymers, block copolymers, and graft copolymers are easily prepared by this system. The polymer obtained in the presence of acrylic monomers are molecules containing the reducing substrates as end- or in-chain groups of the polymer chains formed depending on the functionality of reducing agents. $^{3-9}$

In recent years, there have been many new developments in the synthesis and photochemical studies of novel macrophotoinitiator molecules. These have been designed to have desirable properties such as higher activity or greater curing speed coupled with lower migration rates and/or water solubility. ${ }^{10}$ There is the hope that macrophotoinitiators may be more effective than their low molecular weight analogues, e.g., via the antennae effects (as observed in photosynthesis), reducing the effectiveness of chain termination, enhancing the effectiveness of light absorption by hyperchromism and eliminate odours from cured coatings which emanate from the initiator residues. A more pragmatic reason for assessing their potential is that such initiators will be of value in printing food packaging. ${ }^{11,12}$ From the practical point of view, macrophotoinitiators are used as precursors for block and graft copolymers depending on the position of photoinitiators moiety incorporated. Many polymeric photoinitiators containing side and mid-chain photolabile groups have been synthesized and their photochemistry has been studied in detail. ${ }^{13-17}$

In our previous studies, we synthesized macrophotoinitiators containing end- and mid-chain photoreactive groups by using mono- and dihydroxy functional photoinitiators via atomtransfer radical polymerization (ATRP) and ring-opening polymerization (ROP) methods. The photo treatments of these macrophotoinitiators in the presence of monomers with different chemical nature lead to block copolymers. ${ }^{16-21}$ In this study, an alternative approach to prepare a new mid-chain functional macrophotoinitiator of poly(methyl methacrylate) by redox initiation system was reported. This macrophotoinitiator has the potential for initiating light-induced free radical polymerization.

\section{EXPERIMENTAL}

\section{Materials}

Methyl methacrylate (MMA) (Aldrich) and acrylonitrile (AN) (Aldrich) were dried over calcium hydride and distilled under reduced pressure. Acrylamide (AAm) (Fluka) was recrystallized from ethylacetate before use. Ceric ammonium nitrate (CAN) (Aldrich) was used without further purification. Stock solutions of $\mathrm{Ce}(\mathrm{IV})$ were prepared from CAN in aqueous nitric acid. 2-hydroxy-1-[4-(2-hydroxyethoxy) phenyl]-2-methyl propan-1-one (HE-HMPP), Irgacure 2959 were received from Ciba Specialty Chemicals and used without further purification. Methanol (Lab-Scan), $\mathrm{CH}_{2} \mathrm{Cl}_{2}$ (Merck), and dimethyl sulfoxide (DMSO) (Merck) were used as received.

\section{Redox Polymerization Procedure}

Schlenk tubes of aqueous solutions of MMA containing given amount of HE-HMPP were degassed and purged with nitrogen in three cycles. In order to increase the solubility of

\footnotetext{
${ }^{1}$ Harran University, Science Faculty, Department of Chemistry, Sanliurfa 63190, Turkey

${ }^{2}$ Nevsehir University, Science and Letters Faculty, Department of Chemistry, Nevsehir, 50300, Turkey

*To whom correspondence should be addressed (Fax: +90 414 3440051, E-mail: mustafa@ harran.edu.tr).
} 


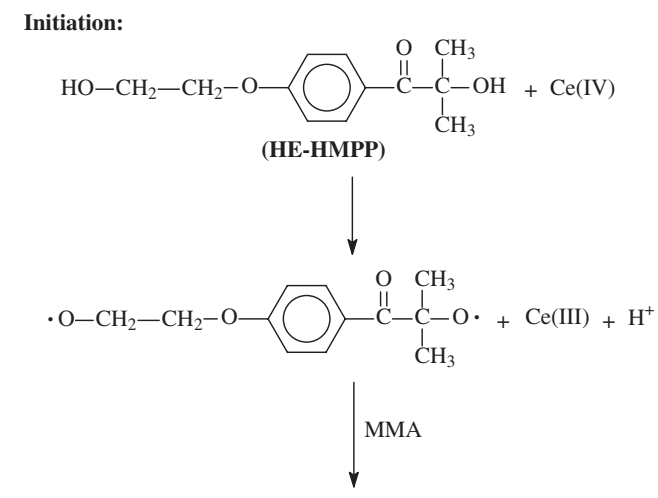

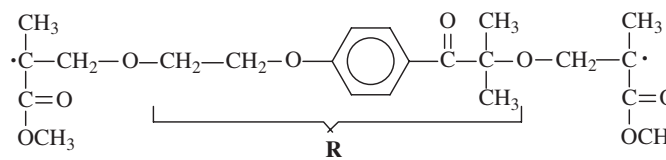

Propagation:

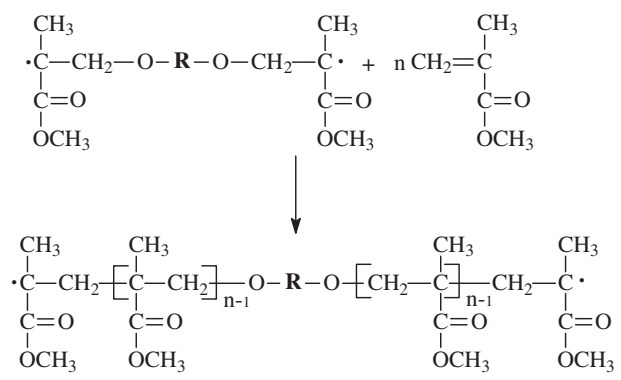

Linear Termination (Oxidative Termination):
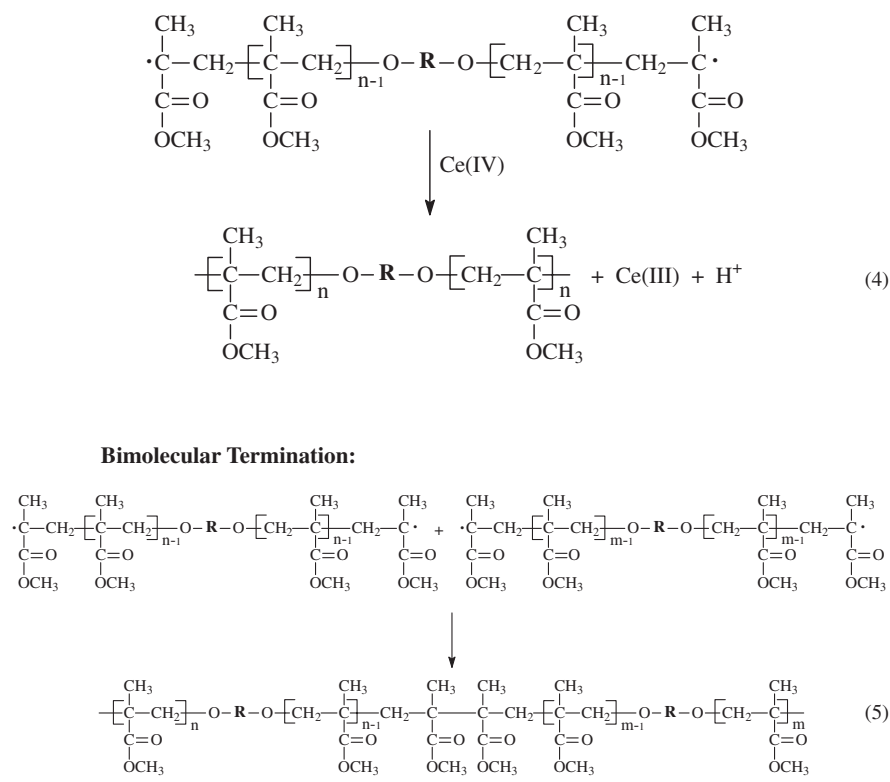

Oxidative Termination of Primary Radicals

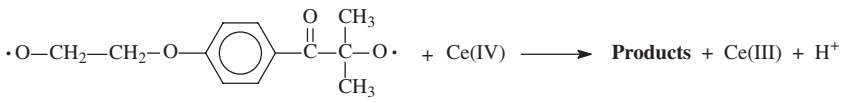

reaction medium approximately $10 \mathrm{mg}$ of tetrabutyl ammonium hydrogen sulphate, TBAHS, was also added. Appropriate solutions of ceric ammonium nitrate in $1 \mathrm{~N}$ nitric acid were then added dropwise to the reaction mixture for about $5 \mathrm{~min}$ while stirring under nitrogen atmosphere. The polymerization experiments were conducted with stirring in dark at $40^{\circ} \mathrm{C}$ for 24h. Macrophotoinitiators of PMMA formed was precipitated from the solution into ten-fold excess methanol.

\section{Photopodegradation Procedure}

Photopodegradation of macrophotoinitiator of PMMA was carried out in DMSO. Macrophotoinitiator of PMMA (100 mg) was dissolved in DMSO (5 mL), and hydroquinone $(0.826 \mathrm{mg}$, $\left.7.5 \times 10^{-3} \mathrm{mmol}\right)$ was added into this solution. The mixture was placed in a pyrex tube and degassed with nitrogen prior to irradiation by a merry go round type photoreactor equipped with 16 Philips $8 \mathrm{~W} / 08$ lamps emitting light nominally at $\lambda>300 \mathrm{~nm}$ and a cooling system. The reaction mixture was irradiated for $2 \mathrm{~h}$ at room temperature. At the end of irradiation, obtained polymer was poured into methanol, filtered and dried.

\section{Photopolymerization Procedure}

Photopolymerizations were carried out in DMSO. Appropriate solutions of monomers (AAm and AN) containing a given amount of macrophotoinitiator were placed in a pyrex tube and degassed with nitrogen prior to irradiation by a merry go round type photoreactor equipped with 16 Philips $8 \mathrm{~W} / 08$ lamps emitting light nominally at $\lambda>300 \mathrm{~nm}$ and a cooling system. At the end of given time, the obtained polymers were poured into methanol, filtered, dried, and weighted. Conversions were determined gravimetrically.

\section{Characterization}

IR spectra were recorded on a Perkin-Elmer spectrum RXI FT-IR spectrophotometer. ${ }^{1} \mathrm{H}$ NMR spectra were recorded on a Bruker $250 \mathrm{MHz}$ spectrometer with $\mathrm{CDCl}_{3}$ as the solvent and tetramethylsilane as the internal standard. UV-vis spectra were recorded on a Shimadzu 1601 spectrophotometer. Fluorescence spectra were registered on a Jasco FP-6300 spectrofluorometer. Gel permeation chromatography (GPC) chromatograms were obtained by using a Waters instrument equipped with a R410 differential refractometer and 600E pump and with THF as the eluent, at a flow rate of $1.0 \mathrm{~mL} / \mathrm{min}$. Molecular weights were calculated by using monodisperse poly(methyl methacrylate) standards.

The rate of polymerization $\left(R_{p}\right)$ was calculated from the weight of polymer by making use of the following equation:

$$
R_{p}=-d[M] / d t=1000 \mathrm{~W} / \mathrm{VtM},
$$

Where $W$ is the weight of polymer, $V$ is the total volume of the reaction mixture, $t$ is the reaction time in seconds and $M$ is the molecular weight of the monomer. 


\section{RESULTS AND DISCUSSION}

Mid-chain macrophotoinitiator of PMMA was synthesized by redox polymerization system. Redox polymerization of MMA with HE-HMPP was carried out in the presence of $\mathrm{Ce}(\mathrm{IV}) / \mathrm{HNO}_{3}$ redox couple in dark at $40{ }^{\circ} \mathrm{C}$ for $24 \mathrm{~h}$. From the relations between experimental conditions, spectroscopic and photodegradation studies of the samples, the following reaction scheme is suggested for the preparation of mid-chain macrophotoinitiator of PMMA. In view of reported role of $\mathrm{Ce}$ (IV) with hydroxyl groups as initiators in redox polymerization this reaction was expected to produce a polymer containing one or two photoactive group in the middle of the chain derived from the photoinitiator (Scheme 1).

By applying the steady-state principle to active intermediates, one can derive the following equation for the rate of polymerization $\left(R_{p}\right)$,

$$
R_{\mathrm{p}}=\frac{k_{\mathrm{p}}}{k_{\mathrm{t}}^{1 / 2}}\left[\frac{k_{\mathrm{i}} k_{\mathrm{d}}[\mathrm{HE}-\mathrm{HMPP}] \mathrm{Ce}(\mathrm{IV})}{k_{\mathrm{i}}[\mathrm{M}]+k_{\mathrm{o}}[\mathrm{Ce}(\mathrm{IV})]}\right]^{1 / 2}[\mathrm{M}]^{3 / 2}
$$

Where, $k_{\mathrm{d}}$ : Rate constant for the radical formation, $k_{\mathrm{i}}$ : Rate constant for initiation, $k_{\mathrm{p}}$ : Rate constant for propagation, $k_{\mathrm{t}}$ : Rate constant for bimolecular termination, and $k_{\mathrm{o}}$ : Rate constant for oxidative termination of primary radicals.

At lower concentration of $\mathrm{Ce}(\mathrm{IV})\left(\leq 10 \times 10^{-3} \mathrm{~mol} \mathrm{~L}^{-1}\right)$, it can be assumed that $k_{\mathrm{o}}[\mathrm{Ce}(\mathrm{IV})]<k_{\mathrm{i}}[\mathrm{M}]$ and the above equation reduces to

$$
R_{\mathrm{p}}=k_{\mathrm{p}}\left(\frac{k_{\mathrm{d}}}{k_{\mathrm{t}}}\right)^{1 / 2}[\mathrm{HE}-\mathrm{HMPP}]^{1 / 2}[\mathrm{Ce}(\mathrm{IV})]^{1 / 2}[\mathrm{M}]
$$

It can be seen from this equation $R_{p}$ is proportional to $[\mathrm{HE}-\mathrm{HMPP}]^{1 / 2},[\mathrm{Ce}(\mathrm{IV})]^{1 / 2}$, and $[\mathrm{M}]$. These relationships were experimentally established for the HE-HMPP-Ce(IV) redox system (Figures 1-3).

Figure 1 shows the dependence of $R_{p}$ on the [HE-HMPP $]^{1 / 2}$. Here the HE-HMPP concentration was varied in the range of $1.0 \times 10^{-3}-25.0 \times 10^{-3} \mathrm{~mol} \mathrm{~L}^{-1}$ whereas all the other param-

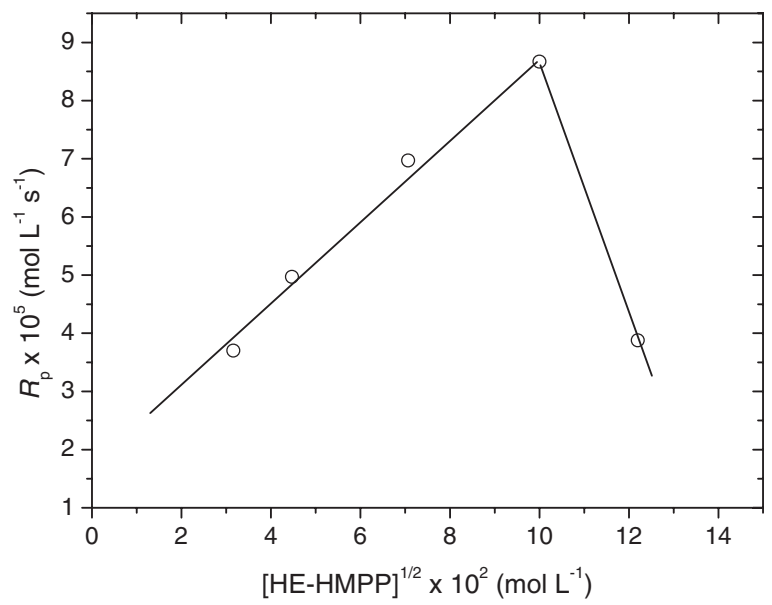

Figure 1. Plot of $R_{\mathrm{p}}$ vs $[\mathrm{HE}-\mathrm{HMPP}]^{1 / 2}$; $[\mathrm{MMA}]=1.88 \mathrm{~mol} \mathrm{~L}^{-1},[\mathrm{Ce}(\mathrm{IV})]=$ $5 \times 10^{-3} \mathrm{~mol} \mathrm{~L}^{-1}$ in $1 \mathrm{~N} \mathrm{HNO}_{3}$ at $40^{\circ} \mathrm{C}$.

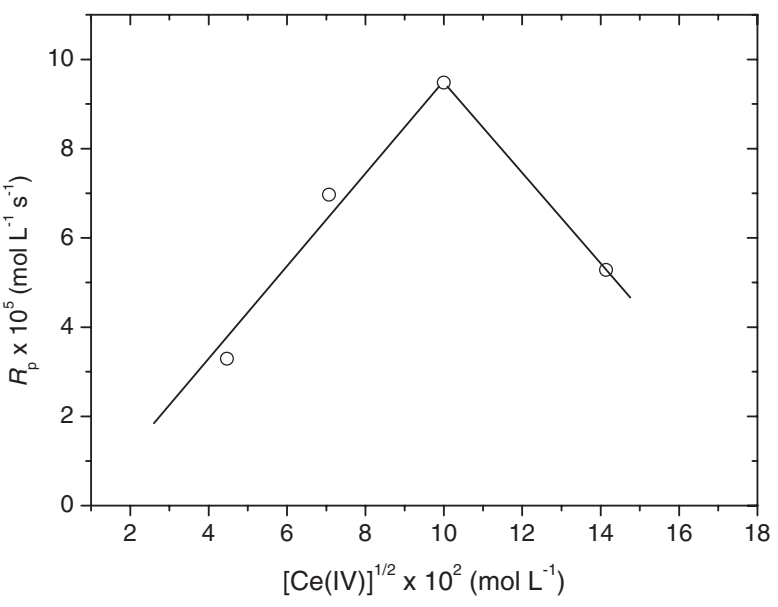

Figure 2. Plot of $R_{\mathrm{p}}$ vs [Ce(IV)] $]^{1 / 2}$; $[\mathrm{HE}-\mathrm{HMPP}]=5 \times 10^{-3} \mathrm{~mol} \mathrm{~L}^{-1}$, $[\mathrm{MMA}]=1.88 \mathrm{~mol} \mathrm{~L}^{-1}$ in $1 \mathrm{~N} \mathrm{HNO}_{3}$ at $40^{\circ} \mathrm{C}$.

eters remained constant. In the absence of HE-HMPP no polymer was formed, therefore it is concluded that the polymerization of MMA is initiated by the redox system consisting of ceric ion and reducing groups on the photoinitiator. Furthermore, $R_{p}$ increased linearly with increasing photoinitiator concentration up to $10.0 \times 10^{-3} \mathrm{~mol} \mathrm{~L}^{-1}$ being directly to the square root of that concentration, clarifying the bimolecular termination. Beyond this point $R_{p}$ degreased with increasing HE-HMPP concentrations. Increasing the HE-HMPP concentration enhanced the primary radicals' concentration, which caused an initial increase in $R_{p}$. Afterward, despite an increase in HE-HMPP concentration, $R_{p}$ degreased, which was due to the pretermination of active chains, as well as termination of primary radicals ${ }^{9}$ with $\mathrm{Ce}(\mathrm{IV})$, which faster than the rate of initiation.

In Figure 2, Ce(IV) concentration was changed in the range of $2.0 \times 10^{-3}-40.0 \times 10^{-3} \mathrm{~mol} \mathrm{~L}^{-1}$ keeping those of other parameters constant. The rate increased linearly with increasing $\mathrm{Ce}(\mathrm{IV})$ concentration toward $10.0 \times 10^{-3} \mathrm{~mol} \mathrm{~L}^{-1}$, being directly proportional to a half order of $\mathrm{Ce}(\mathrm{IV})$ concentration at $40^{\circ} \mathrm{C}$. Initial linear dependence of $R_{p}$ on $\mathrm{Ce}(\mathrm{IV})$ reveals bimolecular termination. The degrease in $R_{p}$ at higher concentrations can be attributed to termination of active chains by Ce(IV). ${ }^{3,9}$

Keeping the other parameters constant, the effect of MMA concentration on $R_{p}$ was investigated by increasing MMA concentration from 0.55 to $2.57 \mathrm{~mol} \mathrm{~L}^{-1}$. A regular increase in $R_{p}$ was observed as MMA concentration increased, the order being unity (Figure 3 ). This unity dependence indicates that bimolecular termination takes places predominantly.

The structure of the macrophotoinitiator of PMMA was confirmed by spectroscopic investigations. The FT-IR spectrum of PMMA macrophotoinitiator contain the characteristic $\mathrm{C}=\mathrm{O}$ ester band and the $\mathrm{C}=\mathrm{O}$ keto group of the photoinitiator moiety at $1731 \mathrm{~cm}^{-1} 1684 \mathrm{~cm}^{-1}$, respectively (Figure 4). In the ${ }^{1} \mathrm{H}$ NMR spectra of the polymer samples can be found not only the specific signals of PMMA, but also absorptions belonging to the rests of initiator. In Figure 5 is shown the ${ }^{1} \mathrm{H}$ NMR 


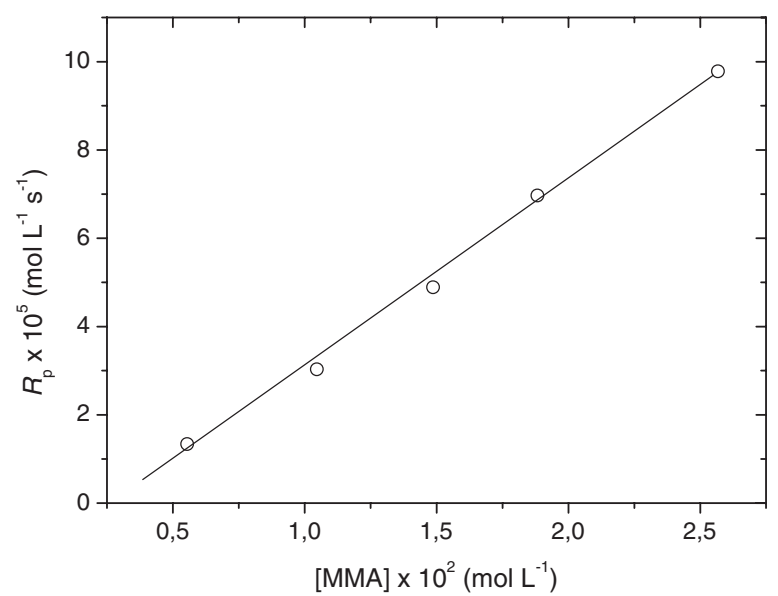

Figure 3. Plot of $R_{\mathrm{p}} v s[\mathrm{MMA}]$; [HE-HMPP] $=5 \times 10^{-3} \mathrm{~mol} \mathrm{~L}^{-1}$, [Ce(IV)] $=$ $5 \times 10^{-3} \mathrm{~mol} \mathrm{~L}^{-1}$ in $1 \mathrm{~N} \mathrm{HNO}_{3}$ at $40^{\circ} \mathrm{C}$.

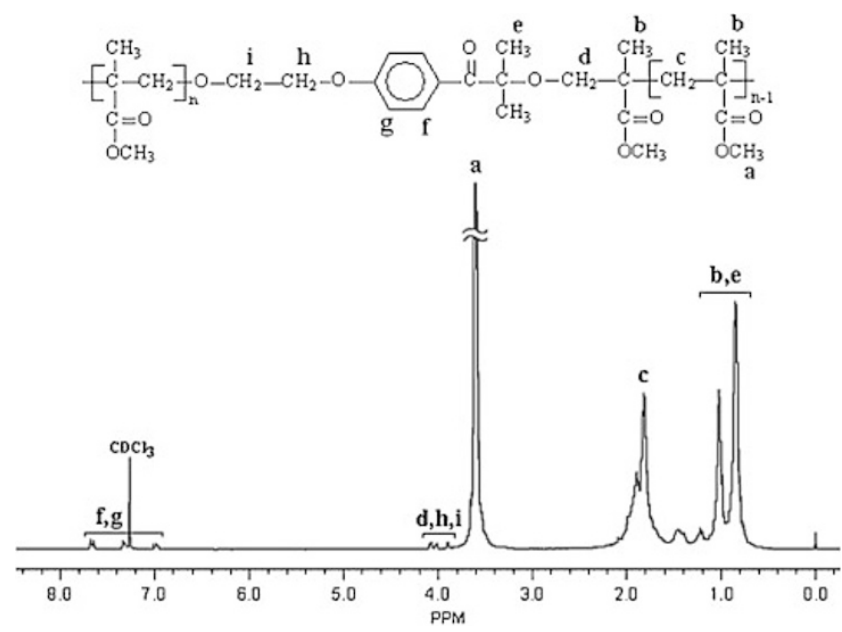

Figure 5. ${ }^{1} \mathrm{H}$ NMR spectrum of PMMA macrophotoinitiator (A polymer obtained from under [HE-HMPP] $=5 \times 10^{-3} \mathrm{~mol} \mathrm{~L}^{-1}$, [MMA] $=$ $0.55 \mathrm{~mol} \mathrm{~L}^{-1},[\mathrm{Ce}(\mathrm{IV})]=5 \times 10^{-3} \mathrm{~mol} \mathrm{~L}^{-1}$ in $1 \mathrm{~N} \mathrm{HNO}_{3}$ at $40^{\circ} \mathrm{C}$ for $24 \mathrm{~h}$. experimental conditions and $M_{\mathrm{n}}=17200 \mathrm{~g} \mathrm{~mol}^{-1}$ ).

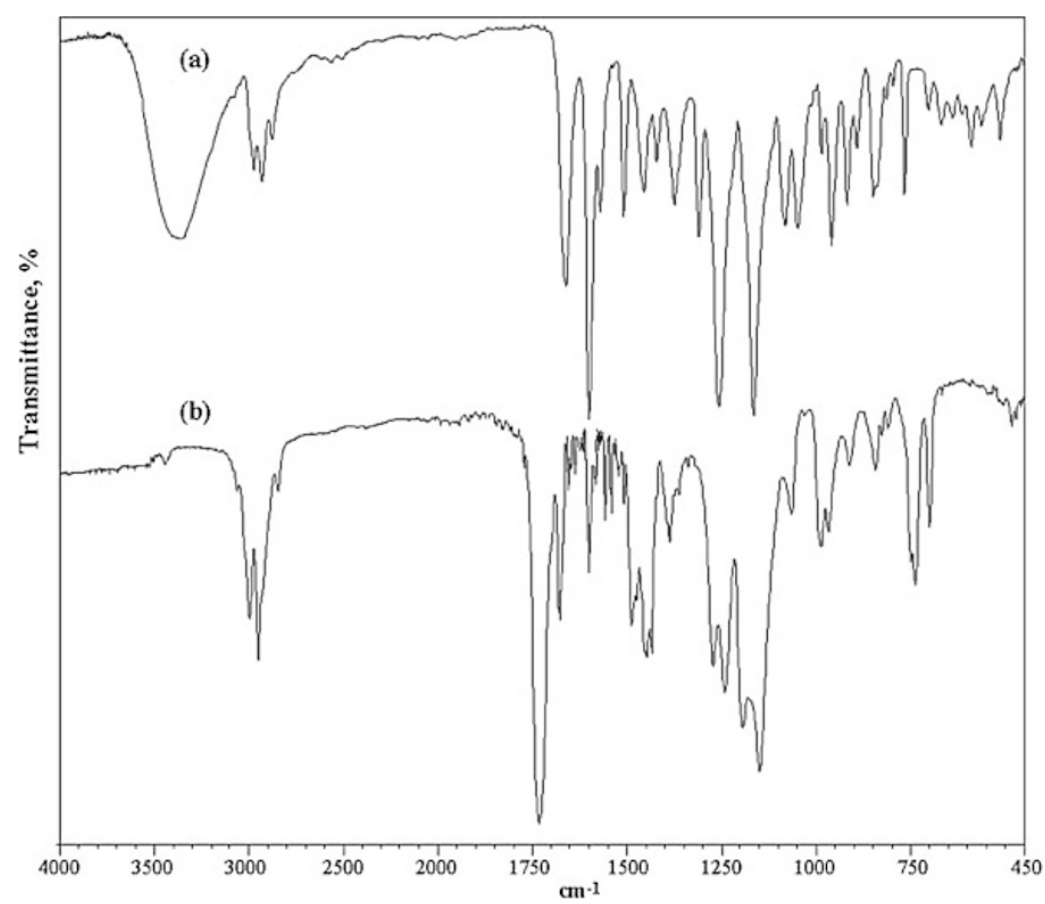

Figure 4. FT-IR spectra of HE-HMPP (a) and PMMA macrophotoinitiator (A polymer obtained from under $[\mathrm{HE}-\mathrm{HMPP}]=5 \times 10^{-3} \mathrm{~mol}^{-1},[\mathrm{MMA}]=0.55$ $\mathrm{mol} \mathrm{L}-1,[\mathrm{Ce}(\mathrm{IV})]=5 \times 10^{-3} \mathrm{~mol} \mathrm{~L}^{-1}$ in $1 \mathrm{~N} \mathrm{HNO}_{3}$ at $40^{\circ} \mathrm{C}$ for $24 \mathrm{~h}$. experimental conditions and $\left.M_{\mathrm{n}}=17200 \mathrm{~g} \mathrm{~mol}^{-1}\right)$ (b).

spectra recorded in $\mathrm{CDCl}_{3}$ evidenced resonance signals of protons of relative intensities corresponding to the number and type of protons.

The incorporation of photoinitiator group into polymers was also evidenced by UV absorption measurements. Figure 6 shows the absorption spectra of precursor, HE-HMPP, together with the PMMA macrophotoinitiator obtained from redox system. It can be seen that the spectrum contains the characteristic absorption band of the precursor $\alpha$-hydroxy phenyl ketone photoinitiator.
Figure 7 shows the fluorescence emission of the related molecules (HE-HMPP and PMMA) in $\mathrm{CH}_{2} \mathrm{Cl}_{2}$ at room temperature. Both spectra show the vibrational structures of the phenyl ketone chromophore. These spectroscopic investigations suggest that the photochromophoric phenyl ketone groups were conserved under the polymerization conditions.

Even more convincing evidence for the presence of the alkoxy phenyl ketone group into polymer chain was obtained from the photodegradation studies of polymers produced by means of redox system. Irradiation in the presence of 


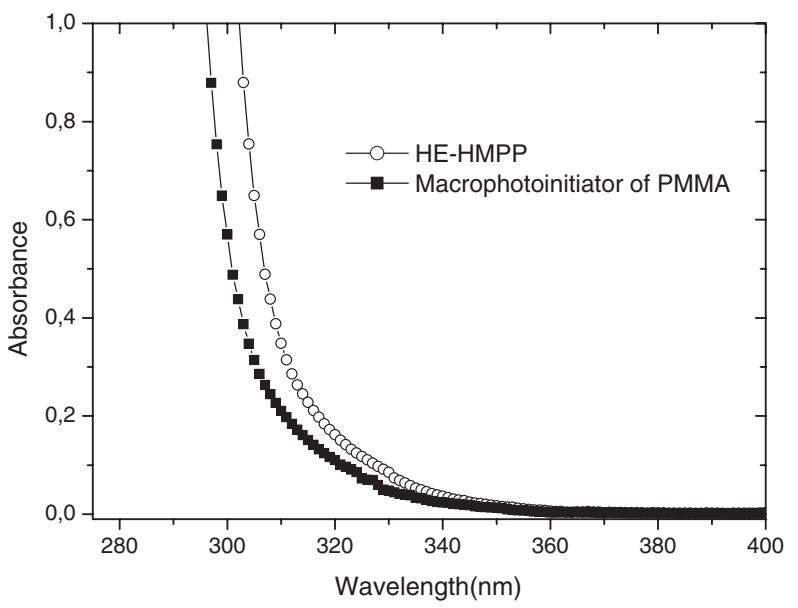

Figure 6. Absorption spectra of HE-HMPP $\left(5 \times 10^{-4} \mathrm{~mol} \mathrm{~L}^{-1}\right)$ and Macrophotoinitiator of PMMA $\left(1.13 \mathrm{~g} \mathrm{~L}^{-1}, M_{\mathrm{n}}=141500 \mathrm{~g} \mathrm{~mol}^{-1}\right)$ in $\mathrm{CH}_{2} \mathrm{Cl}_{2}$.

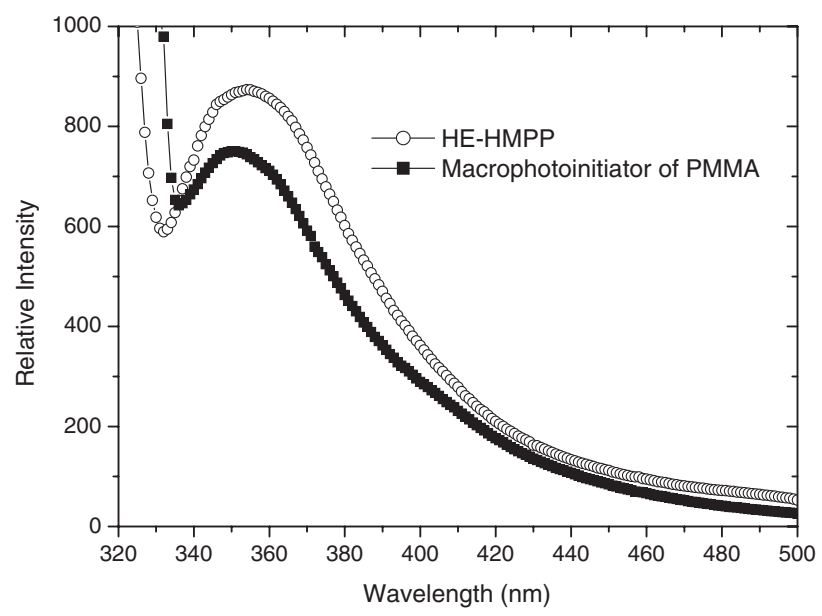

Figure 7. Fluoresence spectra of HE-HMPP $\left(5 \times 10^{-4} \mathrm{~mol} \mathrm{~L}^{-1}\right)$ and Macrophotoinitiator of PMMA $\left(0,122 \mathrm{~g} \mathrm{~L}^{-1}, M_{\mathrm{n}}=141500 \mathrm{~g} \mathrm{~mol}^{-1}\right.$,) in $\mathrm{CH}_{2} \mathrm{Cl}_{2}$, excitation wavelength $=315 \mathrm{~nm}$.

$1.5 \times 10^{-3} \mathrm{~mol} \mathrm{~L}^{-1}$ hydroquinone as the radical scavenger, a significant reduction in the molecular weight was observed. A schematic illustration of photodegradation process was given in Scheme 2 taking into consideration of bimolecular termination. The number of chain scissions per macromolecular, $N_{s}=$ $\left(M_{\mathrm{n} 0} / M_{\mathrm{nt}}\right)-1$, is found to be 3.42 , where $M_{\mathrm{n} 0}(144700)$ and $M_{\mathrm{nt}}$ (32 700) denotes the average molecular weight before and after photolysis (Figure 8). The results from photodegradation studies of macrophotoinitiator of PMMA eliminate linear termination and support bimolecular termination as a major process.

UV absorption measurements and photoinduced free radical polymerization studies of PMMA before and after photolysis confirmed all the alkoxy phenyl ketone groups in the polymer chain were cleaved. Figure 9 show UV absorption of PMMA before and after photolysis. It can be seen that although PMMA obtained before photolysis has absorptions at $\lambda>300 \mathrm{~nm}$, PMMA obtained after photolysis is fully transparent.
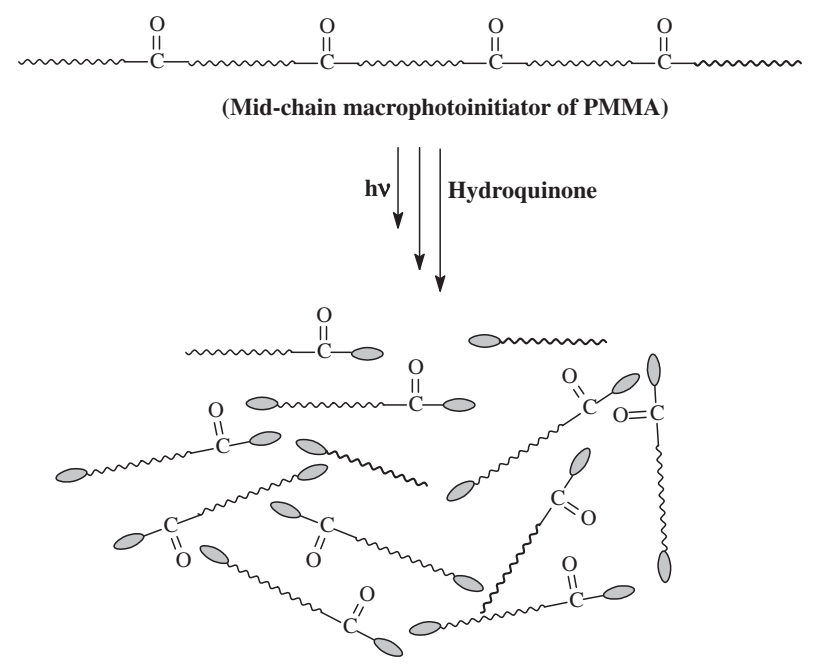

m : PMMA chains

$\bigcirc$ : A radical from hydroquinone

Scheme 2.

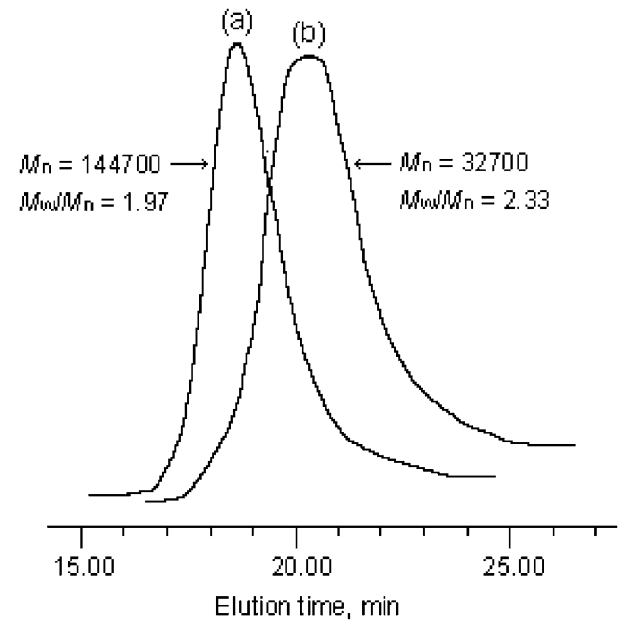

Figure 8. GPC traces of macrophotoinitiator of PMMA before (a) and after photolysis (b).

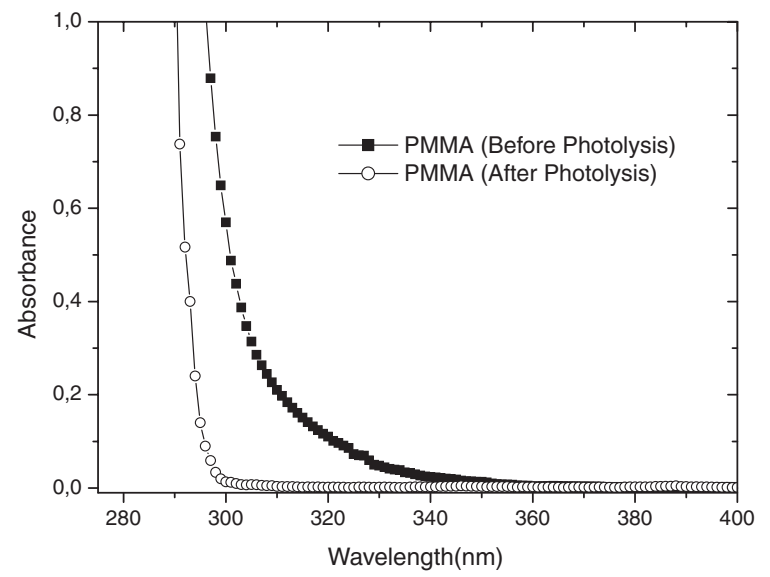

Figure 9. Absorption spectra of PMMA before and after photolysis in $\mathrm{CH}_{2} \mathrm{Cl}_{2}$. 


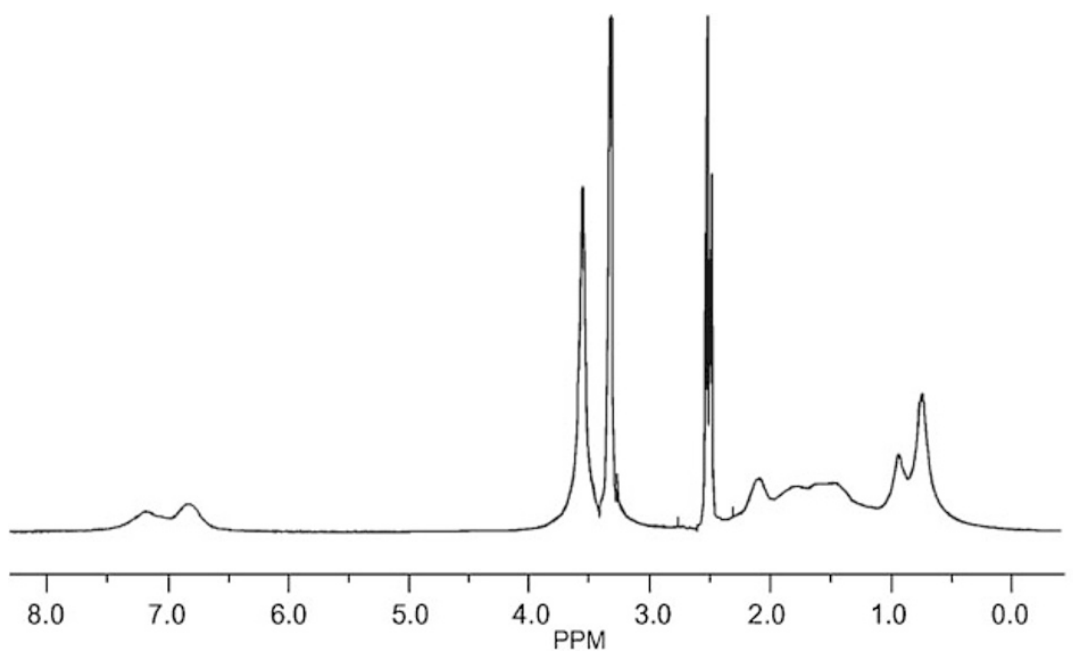

Figure 10. ${ }^{1} \mathrm{H}$ NMR spectrum of PMMA-PAAm block copolymer in DMSO-d $\mathrm{d}_{6}$.

Photoinitiation capability of PMMA macrophotoinitiator and more evidence for the presence of the alkoxy phenyl ketone groups into polymer chain were obtained from the experiments on the polymerization of acrylamide (AAm) and acrylonitrile (AN). A typical photochemically induced polymerization of acrylamide (AAm) $\left(1 \mathrm{~g}, 1.4 \times 10^{-2} \mathrm{~mol}\right)$ in $5 \mathrm{~mL}$ DMSO at room temperature with macrophotoinitiator of PMMA $\left(M_{\mathrm{n}}=144700 \mathrm{~g} \mathrm{~mol}^{-1}, 0.10 \mathrm{~g}, 6.91 \times 10^{-7} \mathrm{~mol}\right)$ produced $28.2 \%$ conversion of AAm after 60 min of irradiation time. In the case of AN monomer in $1 \mathrm{~mL}$ DMSO with the same macrophotoinitiator, PMMA, $\left(M_{\mathrm{n}}=144700 \mathrm{~g} \mathrm{~mol}^{-1}\right)$ at room temperature gave $17.5 \%$ conversion of $\mathrm{AN}$ after $30 \mathrm{~min}$ of irradiation time. A control experiment without the polymeric initiator gave only a negligible amount of polymer after the same irradiation times. In order to prove whether some alkoxy phenyl ketone groups remain after the photolysis of PMMA or not, we used degraded PMMA as a prepolymer for the photopolymerization of AAm and AN monomers. The photoinduced polymerization of AAm and AN with degraded PMMA in DMSO at room temperature produced no polymer after $2 \mathrm{~h}$ irradiation time.

UV irradiation of the polymeric photoiniator caused $\alpha$-scission and yielded polymer bound radicals (Scheme 2) which initiate the polymerization of AAm and AN. Depending on the radicals formed after photolysis, $\mathrm{AB}$ and $\mathrm{ABA}$ type block copolymers of PMMA-PAAm and PMMA-PAN were obtained. The block copolymer structure was assigned by means of NMR spectral measurements. The ${ }^{1} \mathrm{H}$ NMR spectrum of PMMA and PAAm block copolymer displays typical signals

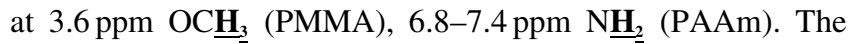
${ }^{1} \mathrm{H}$ NMR spectrum of PMMA and PAN block copolymer displays typical signals at $3.6 \mathrm{ppm} \mathrm{OCH}_{3}$ (PMMA), 3.083.28 ppm CHCN (PAN) (Figure 10).

\section{CONCLUSIONS}

From the kinetic studies, it is concluded that the aqueous polymerization of MMA initiated by Ce(IV)-HE-HMPP redox pair in acidic medium showed bimolecular termination mechanism predominantly. Spectroscopic and photodegradation studies of PAAm revealed that each chain of polymer contains desired photoinitiator groups in the middle. These preliminary results clearly indicate that the ceric ion-photoinitiator redox system is useful for the preparation of polymers having photoinitiator functionality. The results from UV-vis measurements and photopolymerization studies of degraded PMMA clearly indicated no photoinitiator groups remain in the polymer chain. Such prepared macrophotoinitiators can be used in photopolymerization of vinyl monomers such as AAm and $\mathrm{AN}$ for obtaining $\mathrm{AB}$ and $\mathrm{ABA}$ type block copolymer.

Acknowledgment. Financial support of Harran University, Scientific Research Council (HÜBAK) is gratefully acknowledged.

Received: March 3, 2008 Accepted: April 29, 2008 Published: June 18, 2008

\section{REFERENCES}

1. A. S. Sarac, Prog. Polym. Sci., 24, 1149, (1999).

2. U. Yildiz and B. Hazer, Polymer, 41, 539 (2004).

3. C. Yagci and U. Yildiz, Eur. Polym. J., 41, 177 (2005).

4. S. Nagarajan and K. S. V. Srinivasan, Eur. Polym. J., 30, 113 (1994).

5. M. Erim, A. T. Erciyes, I. E. Serhatli, and Y. Yagci, Polym. Bull., 27, 361 (1992).

6. U. Tunca, Eur. Polym. J., 31, 785 (1995).

7. U. Tunca, I. E. Serhatli, and Y. Yagci, Polym. Bull., 22, 483 (1989).

8. H. Macit and B. Hazer, Eur. Polym. J., 43, 3865 (2007).

9. U. Tunca, J. Appl. Polym. Sci., 54, 1491 (1994).

10. T. Corrales, F. Catalina, C. Peinado, and N. S. Allen, J. Photochem. Photobiol., A Chem., 159, 103 (2003).

11. R. S. Davidson, "Exploring the Science, Technology and Applications of U.V. and E.B. Curing” SITA Technology Ltd, London, U.K. 1999.

12. K. Dietliker, "Chemistry and Technology of UV\&EB Formulation for 
Coatings, Inks\&Paints" SITA Technology Ltd, London, U.K. 1991, Vol. III.

13. Y. Yagci, Macromol. Symp., 161, 19 (2000).

14. G. Temel, N. Arsu, and Y. Yagci, Polym. Bull., 57, 51 (2006).

15. Y. Yagci, in "Macromolecular Engineering: Recent Aspects," M. K. Mishra, O. Nuyken, S. Kobayashi, and Y. Yagci, Ed., Plenum Press, New York, 1995, chap. 11.

16. M. Degirmenci, G. Hizal, and Y. Yagci, Macromolecules, 35, 8265 (2002).

17. M. Degirmenci, I. Cianga, and Y. Yagci, Macromol. Chem. Phys.,
203, 1279 (2002).

18. M. Degirmenci, I. Cianga, G. Hizal, and Y. Yagci, Polym. Prepr. Am. Chem. Soc., Div. Polym. Chem., 43, 22 (2002).

19. Y. Yagci and M. Degirmenci, in "Advances in Controlled Radical Polymerization," K. Matyjaszewski, Ed., ACS Symposium Series 854, American Chemical Society, Washington, DC, 2003, p 383.

20. M. Degirmenci, Polym. J., 36, 542 (2004).

21. M. Degirmenci, J. Macromol. Sci., Pure. and Appl. Chem., 42, 21 (2005). 